\title{
ACECLOFENAC-INDUCED STEVENS-JOHNSON SYNDROME AFTER ONE SINGLE DOSE: A MAIDEN CASE REPORT
}

\author{
SAURABH AGARWAL ${ }^{1}$, BALAJI $0^{1}$, NAVIN PATIL ${ }^{2 *}$ \\ Department of Pharmacology, Kasturba Medical College, MAHE Manipal, Manipal, Karnataka, India. Email: navin903@gmail.com
}

Received: 01 December 2017, Revised and Accepted: 14 May 2018

ABSTRACT

Drugs are known to cause various adverse drug reactions involving major organ systems. Skin-related adverse reactions are very common and range from a simple rash to life-threatening condition like Stevens-Johnson syndrome. Various drugs are known to cause skin reactions which include antiepileptics, analgesics, antibiotics, and proton-pump inhibitors. Nonsteroidal anti-inflammatory drugs causing life-threatening conditions such as Stevens-Johnson syndrome and toxic epidermal necrolysis are very rare and only few case reports are published. Hence, we report a case of Aceclofenac-induced Stevens-Johnson syndrome after single time administration in a tertiary care hospital in India.

Keywords: Aceclofenac, Adverse drug reaction, Naranjo’s scaling, Purpuric macules.

(C) 2018 The Authors. Published by Innovare Academic Sciences Pvt Ltd. This is an open access article under the CC BY license (http://creativecommons. org/licenses/by/4. 0/) DOI: http://dx.doi.org/10.22159/ajpcr.2018.v11i9.24067

\section{INTRODUCTION}

Medical treatment is very challenging as every day the treating physician experiences new challenges in treating various conditions as well as encounters new adverse drug reactions to medications. Adverse cutaneous drug reactions are very common in clinical practice, but it often goes unreported. Adverse cutaneous drug reaction is defined as any reaction that causes damage to skin, skin appendages, and mucous membrane and all adverse effects related to drug eruption are included irrespective of the etiology [1]. Nonsteroidal anti-inflammatory drugs (NSAIDs) are known to cause many adverse reactions which include nausea, vomiting, dyspepsia, gastric ulcers, and cutaneous reactions pruritus, morbilliform rashes, urticaria, and photosensitivity [2]. Sometimes, NSAIDs cause lifethreatening conditions such as Stevens-Johnson's syndrome and toxic epidermal necrolysis which are very rare and only few cases have been reported so far in the literature [3]. Hence, we report a rare case of Aceclofenac-induced Stevens-Johnson's syndrome in a tertiary care patient in Southern India.

\section{CASE REPORT}

Informed consent was taken from the patient. The patient was treated by a general practitioner with paracetamol and Aceclofenac on December $25^{\text {th }}, 2016$ for severe fever and body pains with myalgia. Later, December $26^{\text {th }}, 2016$ patient came to our hospital with complaints of oral lesions with fluid-filled blisters all over the body with skin peeling over the upper chest and trunk. Multiple purpuric macules were also noted all over the trunk with additional fluid-filled bullae over the face/nails and scalp. The patient also had complaints of burning sensation in eyes associated with lacrimation and redness along with burning sensation of palms and soles. History also revealed one episode of vomiting. No history of similar episodes in the past or any allergy. The patient was not on any other medications. Immediately, tablet Aceclofenac was suspected as the cause of adverse drug reaction ruling out other causes. Diagnosis of Aceclofenac-induced Stevens-Johnson syndrome was made and the patient was treated with fusidic acid ointment and fluticasone ointment thrice daily to be applied locally till the lesions subside. He was also started on Wysolone $20 \mathrm{mg}$ oral tablet in the morning along with candid mouthwash. He was also started with ciprofloxacin eye drops along with other supportive measures. Moreover, the patient was asked to review after 2 weeks. The patient showed significant improvement on his next visit.

\section{DISCUSSION}

Stevens-Johnson syndrome is very rare and is said to be a lifethreatening skin condition. Incidence ranges from 2.6 to 7.1 persons per million populations per year in the United States [4]. Various drugs are implicated in causing Stevens-Johnson syndrome and incidence ranges from 75 to $90 \%$ for drug-induced etiology [5]. The most common drugs implicated include NSAIDs, anti-epileptics, and antimicrobials. Based on the body surface area involved Stevens-Johnson syndrome (SJS) and toxic epidermal necrolysis (TEN) is classified with former involving $<10 \%$ and later involving $>30 \%$, respectively [5]. Sometimes, both these conditions overlap together which is called SJS-TEN overlap. It is diagnosed usually with the help of clinical signs and histopathological diagnosis. Usual mechanisms include reactive drug metabolites and immunological reactions. Interactions between FAS (CD 95) and CD95 ligand are said to play a major role. This interaction takes place in the epidermal layer of the skin. The TEN is more common in women compared to men while the reverse is true in case of SJS. Antibiotics have an incidence of 34\% in causing SJS followed by analgesics with an incidence of 33\% [6].

Aceclofenac is a NSAIDs mainly used in the management of pain in rheumatic disorders. It acts by inhibiting the cyclooxygenase enzyme system thereby inhibiting prostaglandins synthesis. It helps in reducing inflammation as well as in pain control. It is associated with side effects which include gastrointestinal (GI) disturbances, paresthesias, vertigo, and tremor. It is also known to cause cutaneous adverse reactions ranging from rashes, pruritus, urticaria, and hypersensitivity reactions [7]. There are only few case reports on Aceclofenac-induced Stevens-Johnson's syndrome/toxic epidermal necrolysis [8,9]. According to severe cutaneous adverse reactions to drugs, study group piroxicam and tenoxicam had the highest risk of SJS/TEN with diclofenac and ibuprofen having the lowest risk. According to a study by Lapeyre-Mestre et al., Aceclofenac caused many adverse reactions including GI disturbances and cutaneous reactions, but liver toxicity was found to be the most common reported adverse reaction [10]. There are many prognostic factors for SJS, but those of paramount important include age at diagnosis, extent of skin necrolysis, and serum urea level [9]. Mortality with SJS was found to be around 1 to $3 \%$ compared to higher mortality rates observed with TEN [9]. A large multicenter study also revealed early administration of glucocorticoids together with withdrawal of offending agent helps in better treatment prognosis and patient survival rates [9]. 
In our patient, the lesions appeared within 1 day of treatment with Aceclofenac. Other causes of SJS/TEN were ruled including history of intake of drugs known to cause SJS/TEN. Aceclofenac was stopped immediately and the patient was started on Wysolone $20 \mathrm{mg}$ along with proper treatment of skin lesions along with supportive measures which included electrolyte management. Causality assessment was done using Naranjo's scale [11], and a probable causal relationship was established. The adverse drug reaction was found be moderately severe and preventable as per Hartwig's scale and Thornton's scale, respectively $[12,13]$.

\section{CONCLUSION}

Since SJS/TEN is a life-threatening cutaneous reaction leading to mortality, proper care of the patient along with stopping the offending agent after ruling out other causes should be of foremost importance. Further, clinical trial can be done in India to find out the incidence of SJS/TEN associated with NSAIDs.

\section{CONFLICTS OF INTEREST}

The authors declare that they have no conflicts of interest.

\section{AUTHOR'S CONTRIBUTION}

Thanks to Dr. Navin for helping and also to the department of pharmacology.

\section{REFERENCES}

1. Nayak S, Acharjya B. Adverse cutaneous drug reaction. Indian J Dermatol 2008;53:2.

2. Stevenson DD. Diagnosis, prevention, and treatment of adverse reactions to aspirin and nonsteroidal anti-inflammatory drugs. J Allergy Clin Immunol 1984;74:617-22.
3. Borchers AT, Lee JL, Naguwa SM, Cheema GS, Gershwin ME. Stevens-Johnson syndrome and toxic epidermal necrolysis. Autoimmun Rev 2008;7:598-605

4. Strom BL, Carson JL, Halpern AC, Schinnar R, Snyder ES, Shaw M, et al. A population-based study of Stevens-Johnson syndrome. Incidence and antecedent drug exposures. Arch Dermatol 1991;127:831-8.

5. Bastuji-Garin S, Rzany B, Stern RS, Shear NH, Naldi L, Roujeau JC, et al. Clinical classification of cases of toxic epidermal necrolysis, Stevens-Johnson syndrome, and erythema multiforme. Arch Dermatol 1993;129:92-6.

6. Schöpf E, Stühmer A, Rzany B, Victor N, Zentgraf R, Kapp JF, et al. Toxic epidermal necrolysis and Stevens-Johnson syndrome. An epidemiologic study from West Germany. Arch Dermatol 1991;127:839-42.

7. Dooley M, Spencer CM, Dunn CJ.Aceclofenac. Drugs 2001;61:1351-78.

8. Ludwig C, Brinkmeier T, Frosch PJ. Exudative erythema multiforme with transition to a toxic epidermal necrolysis after taking aceclofenac (Beofenac). Dtsch Med Wochenschr 2003;128:487-90.

9. Ameen KH, Pinninti R, Jami S. Aceclofenac induced StevensJohnson/toxic epidermal necrolysis overlap syndrome. J Pharmacol Pharmacother 2013;4:69.

10. Lapeyre-Mestre M, Grolleau S, Montastruc JL, Association Française des Centres Régionaux de Pharmacovigilance (CRPV). Adverse drug reactions associated with the use of NSAIDs: A case/noncase analysis of spontaneous reports from the French pharmacovigilance database 2002-2006. Fundam Clin Pharmacol 2013;27:223-30.

11. Naranjo CA, Busto U, Sellers EM, Sandor P, Ruiz I, Roberts EA, et al. A method for estimating the probability of adverse drug reactions. Clin Pharmacol Ther 1981;30:239-45.

12. Hartwig SC, Siegel J, Schneider PJ. Preventability and severity assessment in reporting adverse drug reactions. Am J Hosp Pharm 1992;49:2229-32.

13. Schumock GT, Thornton JP. Focusing on the preventability of adverse drug reactions. Hosp Pharm 1992;27:538. 